\title{
Combination of simvastatin and bone morphogenetic protein-2 enhances the differentiation of osteoblasts by regulating the expression of phospho-Smad1/5/8
}

\author{
JUN-BEOM PARK \\ Department of Periodontics, Seoul St. Mary's Hospital, College of Medicine, \\ The Catholic University of Korea, Seoul, Republic of Korea
}

Received March 18, 2012; Accepted May 22, 2012

DOI: $10.3892 /$ etm.2012.590

\begin{abstract}
Statins inhibit 3-hydroxy-3-methylglutarylcoenzyme A reductase, which catalyzes the conversion of 3-hydroxy-3-methylglutaryl-coenzyme A to mevalonate, a rate-limiting step in cholesterol synthesis. A number of studies have demonstrated bone-promoting effects when simvastatin is applied locally with different carriers in various animal models. In the prsent study, the dose-dependent impact of simvastatin and bone morphogenetic protein-2 (BMP-2) on the cellular proliferation and differentiation of osteoprecursor cells was evaluated. The alkaline phosphatase activity (ALP) test was performed to assess differentiation, and protein expression related to bone formation, including that of phospho-Smad1/5/8 (pSmad1/5/8), was measured using western blot analysis to evaluate the underlying mechanism(s). Cultures grown in the presence of $0.1 \mu \mathrm{M}$ simvastatin with $60 \mathrm{ng} / \mathrm{ml}$ BMP-2 exhibited the highest value for ALP activity. The results of the western blot analysis indicated that the addition of simvastatin upregulated $\mathrm{pSmad} 1 / 5 / 8$ expression and the combination of $0.1 \mu \mathrm{M}$ simvastatin and $60 \mathrm{ng} / \mathrm{ml}$ BMP-2 produced a significant increase in protein expression. Based on these findings, it was concluded that the combination of simvastatin and BMP-2 produced positive effects on the differentiation of osteoprecursor cells. The results also suggest that the combination of simvastatin and BMP-2 has synergistic effects that are achieved through the BMP pathway by enhancing the expression of $\mathrm{pSmad} 1 / 5 / 8$ expression.
\end{abstract}

\section{Introduction}

Statins inhibit 3-hydroxy-3-methylglutaryl-coenzyme A reductase, which catalyzes the conversion of 3-hydroxy-

Correspondence to: Professor Jun-Beom Park, Department of Periodontics, Seoul St. Mary's Hospital, College of Medicine, The Catholic University of Korea, 505 Banpo-dong, Seocho-gu, Seoul 137-040, Republic of Korea

E-mail: jbassoonis@yahoo.co.kr

Key words: bone morphogenetic protein-2, differentiation, osteoblasts, proliferation, simvastatin 3-methylglutaryl-coenzyme A to mevalonate, a rate-limiting step in cholesterol synthesis (1). In addition to their efficacy for cholesterol lowering, statins have been reported to have anabolic effects on bone. A number of studies have demonstrated a bone-promoting effect when simvastatin was applied locally with different carriers in various animal models (2).

Previous studies have provided information regarding effective dosage and certain underlying mechanisms $(1,3)$. It was shown that enhanced expression of bone morphogenetic protein-2 (BMP-2) mRNA is achieved by simvastatin, and that this may trigger osteoblast differentiation (4). However, the combined effects of simvastatin and BMP- 2 on the differentiation of osteoblasts have not been fully investigated.

This study aimed to examine the dose-dependent impact of simvastatin and BMP-2 on the differentiation of osteoprecursor cells. In addition, the impact of the molecules on cell viability was also evaluated. The alkaline phosphatase activity (ALP) test was performed to assess differentiation, and protein expressions related to bone formation, including that of phospho-Smad1/5/8 (pSmad1/5/8), were measured using western blot analysis to evaluate the underlying mechanism. To the author's knowledge, this investigation is the first to elucidate the combined effect of simvastatin and BMP-2 on the expression of $\mathrm{pSmad} 1 / 5 / 8$ in relation to osteoblast differentiation.

\section{Materials and methods}

Cell culture. Murine osteoprecursor (MC3T3-E1) cells were cultured in $\alpha$-minimum essential medium ( $\alpha \mathrm{MEM}$ ) supplemented with $10 \%$ fetal bovine serum and antibiotics $(100 \mathrm{U} / \mathrm{ml}$ of penicillin and streptomycin $100 \mu \mathrm{g} / \mathrm{ml}$ ) (Invitrogen, Carlsbad, CA, USA). To induce osteogenic differentiation, culture media were replaced with osteogenic differentiation medium [ $\alpha$ MEM supplemented with $50 \mu \mathrm{g} / \mathrm{ml}$ ascorbic acid and $10 \mathrm{mM} \beta$-glycerolphosphate (Sigma, St. Louis, MO, USA)]. The cultures were maintained in a humidified atmosphere with $5 \% \mathrm{CO}_{2}$ and $95 \%$ air at $37^{\circ} \mathrm{C}$. Simvastatin was dissolved in dimethyl sulfoxide (DMSO; Sigma) and filter-sterilized. The water used was distilled and deionized $\left(\mathrm{ddH}_{2} \mathrm{O}\right)$. In order to minimize any difference in cellular growth and differentiation between the controls and treated cultures, an equal amount of 
DMSO was applied in the control and treated cultures of each experiment.

Cellular proliferation. Cells were plated at a density of $1.0 \times 10^{4}$ cells $1 \mathrm{ml} /$ well in 12 -well plates, and the cultures were stimulated with simvastatin and BMP-2 at final concentrations ranging from 0.1 to $1 \mu \mathrm{M}$ for simvastatin and from 6 to $60 \mathrm{ng} / \mathrm{ml}$ for BMP-2, respectively. The effects of simvastatin and BMP-2 on the cellular proliferation of the osteoprecursor cells were assessed at day 5. The 3-[4,5-dimethylthiazol-2-yl]2,5-diphenyltetrazolium bromide (MTT) reagents $(0.5 \mathrm{mg} / \mathrm{ml})$ were then added, and the cells were incubated for $1 \mathrm{~h}$ at $37^{\circ} \mathrm{C}$. The mitochondrial activities of the cells after various concentrations of simvastatin and BMP-2 treatments were determined by colorimetric assay, which detects the conversion of MTT to an insoluble blue formazan product. The solubilizing reagent, DMSO (1 ml) was added to all wells and mixed thoroughly to dissolve the blue crystals. After ensuring that all crystals were dissolved, the plates were read on a microplate reader using a test wavelength of $560 \mathrm{~nm}$ against a reference wavelength of $670 \mathrm{~nm}$.

Alkaline phosphatase (ALP) activity assays. The ALP assay for osteoblast differentiation was performed on day 5 of culture. Cells that were pre-lysed in a radioimmunoprecipitation assay buffer were sonicated for $20 \mathrm{sec}$ at $4^{\circ} \mathrm{C}$. The lysate was centrifuged at $14,000 \mathrm{rpm}$ for $10 \mathrm{~min}$ at $4^{\circ} \mathrm{C}$ in a microcentrifuge to remove cellular debris. An enzyme activity assay was performed in an assay buffer containing $10 \mathrm{mM}$ p-nitrophenylphosphate as substrate.

Western blot analysis. Osteoprecusor cells were washed twice with ice-cold phosphate-buffered saline and solubilized in lysis buffer. The lysates were centrifuged at $14,000 \mathrm{rpm}$ for $20 \mathrm{~min}$ at $4^{\circ} \mathrm{C}$ to remove the nuclear pellet. The supernatants were boiled in a sodium dodecyl sulfate sample buffer containing $\beta$-mercaptoethanol. Equal quantities of cell extracts were separated using sodium dodecyl sulfate-polyacrylamide gel electrophoresis and transferred onto polyvinylidene fluoride (PVDF) microporous membranes (Immobilon-P membranes; Millipore Corporation, Billerica, MA, USA). Membranes were then blocked for at least $1 \mathrm{~h}$ in $0.1 \%(\mathrm{v} / \mathrm{v})$ phosphate-buffered saline and Tween-20 (Tween-20/phosphate-buffered saline) containing $5 \%(\mathrm{w} / \mathrm{v})$ powdered milk before being probed with the desired antibodies diluted in the same buffer at the recommended concentrations. The membrane was incubated with horseradish peroxidase-conjugated secondary antibody. The washed blot was developed using enhanced chemiluminescence reagent. Antibodies against TGF- $\beta 1, \mathrm{pSmad} 1 / 5 / 8$ and $\beta$-actin and secondary antibodies linked with horseradish peroxidase were purchased from Cell Signaling Technology, Inc. (Danvers, MA, USA), BD Pharmingen (San Diego, CA, USA) and Santa Cruz Biotechnology (Santa Cruz, CA, USA).

Statistical analysis. Results are expressed as the means \pm SD of the experiments and a one-way analysis of variance (ANOVA) was used to determine differences between groups using a commercially available program (PASW Statistics 18; SPSS Inc., Chicago, IL, USA). Statistical significance was set at $\mathrm{P}<0.05$

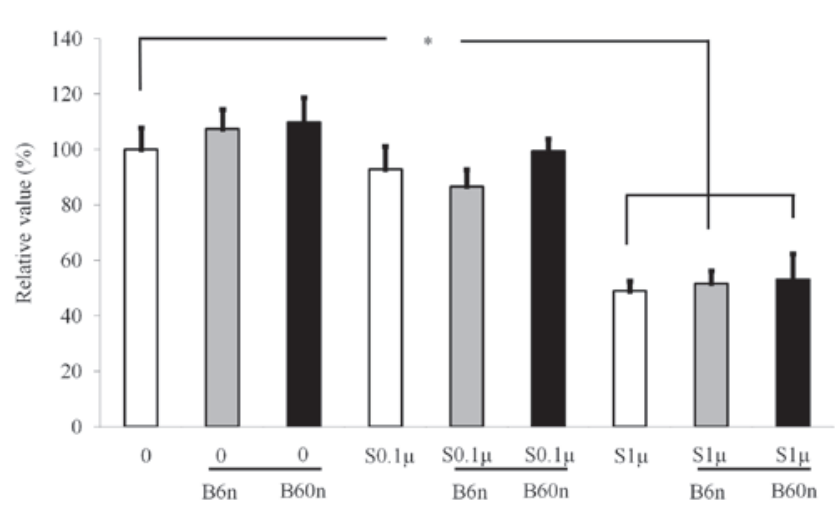

Figure 1. Determination of cellular proliferation using the MTT assay. ${ }^{*} \mathrm{P}<0.05$ compared to the control (non-loaded) group. B, BMP-2; S, simvastatin.

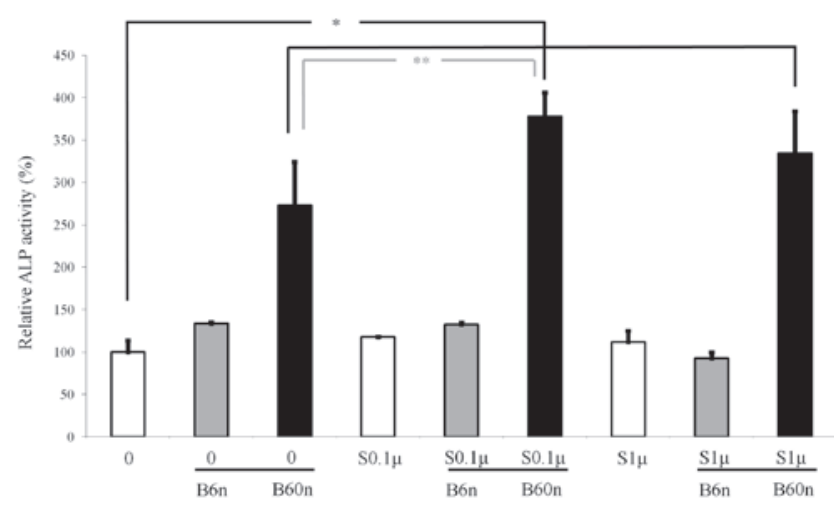

Figure 2. Relative value of ALP activity. ${ }^{*} \mathrm{P}<0.05$ compared with the control (non-loaded) group; ${ }^{* *} \mathrm{P}<0.05$ compared with the $60 \mathrm{ng} / \mathrm{ml} \mathrm{BMP}-2$ group. B, BMP-2; S, simvastatin.

\section{Results}

Cellular proliferation. Cultures growing in the presence of BMP-2 at 6 and $60 \mathrm{ng} / \mathrm{ml}$ did not show any changes in the MTT assays, and there were no significant differences among the three groups (Fig. 1). However, addition of $1 \mu \mathrm{M}$ simvastatin significantly reduced the growth of the cells.

ALP activity assay. The ALP activity was increased when cells were treated with simvastatin, with the highest value at $0.1 \mu \mathrm{M}$ (Fig. 2). The ALP activity increased accordingly when 6 or $60 \mathrm{ng} / \mathrm{ml}$ BMP-2 was added to the simvastatin-unloaded and 0.1 and $1 \mu \mathrm{M}$ simvastatin groups, with a significantly higher value observed at $60 \mathrm{ng} / \mathrm{ml}$ BMP-2. Similarly, cultures grown in the presence of $60 \mathrm{ng} / \mathrm{ml}$ of BMP-2 displayed an increased ALP activity when 0.1 or $1 \mu \mathrm{M}$ simvastatin was added. The highest ALP activity was achieved when $0.1 \mu \mathrm{M}$ simvastatin and $60 \mathrm{ng} / \mathrm{ml}$ BMP-2 were loaded simultaneously.

Western blot analysis. Western blot analysis was performed to detect the protein expression following treatment with simvastatin and BMP-2. The results showed that addition of BMP-2 amplified the expression of pSmad1/5/8 (Fig. 3). Similarly, the addition of simvastatin increased the expression of $\mathrm{pSmad} 1 / 5 / 8$ with the highest value observed in the $0.1 \mu \mathrm{M}$ 


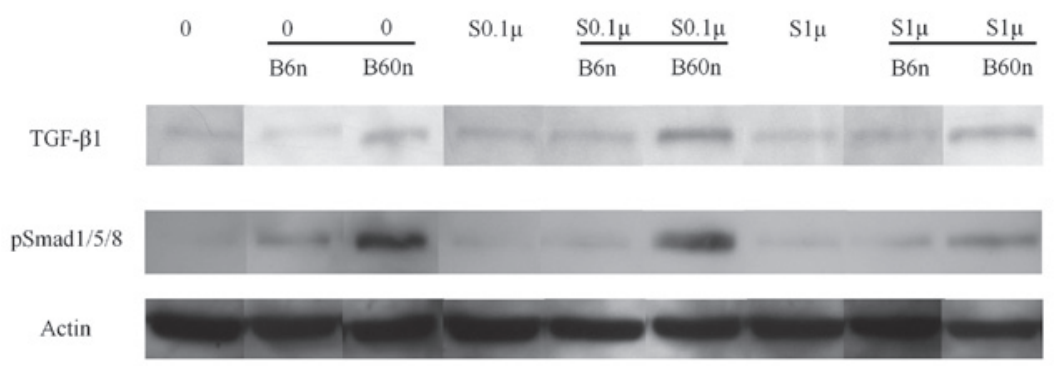

Figure 3. Western blot analysis for detection of the protein expression of TGF- $\beta 1$, pSmad1/5/8 and $\beta$-actin. B, BMP-2; S, simvastatin.

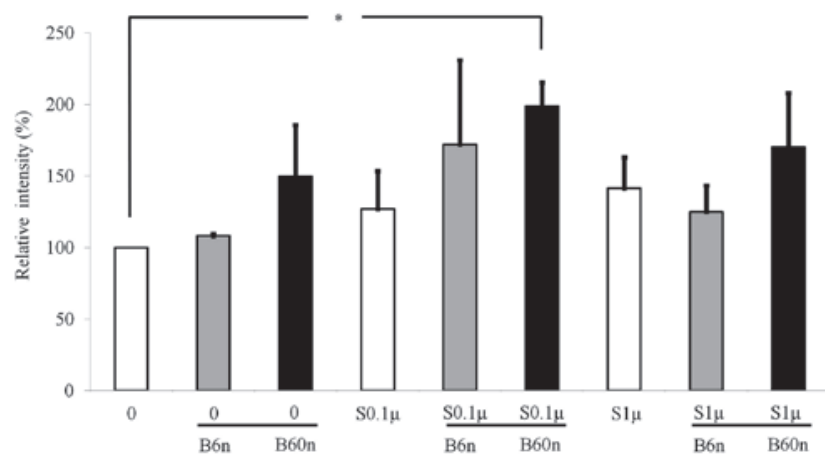

Figure 4. Quantitative analysis of the protein expression of $\mathrm{pSmad} 1 / 5 / 8$ after normalization with $\beta$-actin levels by densitometry. ${ }^{*} \mathrm{P}<0.05$ compared to the control (non-loaded) group. B, BMP-2; S, simvastatin.

simvastatin group. Normalization of the protein expression levels revealed that the group treated with $60 \mathrm{ng} / \mathrm{ml} \mathrm{BMP-2}$ yielded $149.6 \pm 36.1 \% \mathrm{pSmad} 1 / 5 / 8$ expression. The expression of $\mathrm{pSmad} 1 / 5 / 8$ increased when BMP-2 was co-delivered with simvastatin. The relative values of $0.1 \mu \mathrm{M}$ simvastatin $+60 \mathrm{ng} / \mathrm{ml} \mathrm{BMP}-2$ and $1 \mu \mathrm{M}$ simvastatin $+60 \mathrm{ng} / \mathrm{ml} \mathrm{BMP}-2$ were $198.8 \pm 16.5$ and $170.4 \pm 37.6 \%$, respectively (Fig. 4).

\section{Discussion}

In this report, the combined effects of simvastatin and BMP-2 on cell viability, differentiation and protein expression of osteoblast progenitor cells were examined under predetermined concentrations of simvastatin $(0.1$ and $1 \mu \mathrm{M})$ and BMP-2 (6 and $60 \mathrm{ng} / \mathrm{ml})$. In addition, evaluations were carried out to identify whether the combination of simvastatin and BMP-2 produces effects additive, synergistical or competitive effects.

The MTT assay was used to evaluate cell viability, since it is considered a sensitive assay with which to assess osteoblast proliferation through the determination of mitochondrial dehydrogenase activity $(3,5)$. Equal amounts of DMSO were loaded to each culture to offset the effect of the vehicle (3). The results indicated that there was significant reduction in obtained MTT values, suggesting that $1 \mu \mathrm{M}$ simvastatin may effect the number of cells in this cultured condition. It can be suggested that high concentrations of simvastatin may exert a toxic effect on the cells (6); however, there may be variations in doses related to the deleterious effect, depending on the type of cells, the stage of differentiation and the culturing period $(3,6,7)$.
ALP activity, which is an early marker of osteoblastic cell differentiation, was used to evaluate the osteoblast differentiation (8). In previous experiments, significant effects of simvastatin on osteoblast differentiation in MC3T3-E1 cells were observed at concentrations of 0.01 and $0.1 \mu \mathrm{M}$ (4). Similarly, a significant increase in ALP activity was noted in the $0.1 \mu \mathrm{M}$ simvastatin group. The highest value was achieved when $60 \mathrm{ng} / \mathrm{ml}$ BMP-2 was loaded with $0.1 \mu \mathrm{M}$ simvastatin. When $60 \mathrm{ng} / \mathrm{ml} \mathrm{BMP}-2$ or $0.1 \mu \mathrm{M}$ simvastatin was loaded alone, the relative increase in ALP activity was 177.2 and $17.9 \%$, respectively. However, when $60 \mathrm{ng} / \mathrm{ml}$ BMP-2 was combined with $0.1 \mu \mathrm{M}$ simvastatin, the relative increase reached $278.2 \%$, indicating that these two molecules synergistically enhance osteoblast differentiation.

Western blot analysis was performed to detect protein expression of $\mathrm{pSmad} 1 / 5 / 8$, and to provide information regarding the possible mechanism. It has been reported that simvastatin may enhance osteoblast differentiation through BMP signaling (9). When BMP-2 and simvastatin were delivered simultaneously, the highest protein expression value was achieved when $60 \mathrm{ng} / \mathrm{ml}$ BMP-2 was loaded with $0.1 \mu \mathrm{M}$ simvastatin. The relative expression levels of $60 \mathrm{ng} / \mathrm{ml} \mathrm{BMP-2}$ or $0.1 \mu \mathrm{M}$ simvastatin were 149.6 and $127.0 \%$, respectively. However, when $60 \mathrm{ng} / \mathrm{ml}$ BMP-2 was combined with $0.1 \mu \mathrm{M}$ simvastatin, the relative expression level reached $198.8 \%$. Taken together, these results indicate that simvastatin and BMP-2 provide osteo-inductive effects through the BMP pathway by enhancing $\mathrm{pSmad} 1 / 5 / 8$ expression.

In conclusion, the combination of simvastatin and BMP-2 produces positive effects on the differentiation of osteoprecursor cells. The results also suggest that the combination of simvastatin and BMP-2 has synergistic effects that are achieved via the BMP pathway by enhancing the expression of $\mathrm{pSmad} 1 / 5 / 8$.

\section{Acknowledgements}

This work was supported by the Bioethics Expert Development Fund by the Committee for Life in the Archdiocese of Seoul.

\section{References}

1. Chen PY, Sun JS, Tsuang YH, Chen MH, Weng PW and Lin FH: Simvastatin promotes osteoblast viability and differentiation via Ras/Smad/Erk/BMP-2 signaling pathway. Nutr Res 30: 191-199, 2010.

2. Park JB: The use of simvastatin in bone regeneration. Med Oral Patol Oral Cir Bucal 14: e485-488, 2009. 
3. Park JB, Zhang H, Lin CY, et al: Simvastatin maintains osteoblastic viability while promoting differentiation by partially regulating the expressions of estrogen receptors alpha. J Surg Res 174: 278-283, 2012.

4. Maeda T, Matsunuma A, Kawane T and Horiuchi N: Simvastatin promotes osteoblast differentiation and mineralization in MC3T3-E1 cells. Biochem Biophys Res Commun 280: 874-877, 2001.

5. Meleti Z, Shapiro IM and Adams CS: Inorganic phosphate induces apoptosis of osteoblast-like cells in culture. Bone 27: 359-366, 2000

6. Baek KH, Lee WY, Oh KW, et al: The effect of simvastatin on the proliferation and differentiation of human bone marrow stromal cells. J Korean Med Sci 20: 438-444, 2005.
7. Moursi AM, Winnard PL, Winnard AV, Rubenstrunk JM and Mooney MP: Fibroblast growth factor 2 induces increased calvarial osteoblast proliferation and cranial suture fusion. Cleft Palate Craniofac J 39: 487-496, 2002.

8. Park JB: Effects of fibroblast growth factor 2 on osteoblastic proliferation and differentiation by regulating bone morphogenetic protein receptor expression. J Craniofac Surg 22: $1880-1882,2011$

9. Lee MH, Kim YJ, Kim HJ, et al: BMP-2-induced Runx2 expression is mediated by Dlx 5 , and TGF-beta 1 opposes the BMP-2-induced osteoblast differentiation by suppression of Dlx 5 expression. J Biol Chem 278: 34387-34394, 2003. 